\title{
Robert L. Dawson, Confiscations at customs: banned books and the French booktrade during the last years of the Ancien Régime
}

\section{Regina Bochenek-Franczakowa}

\section{(2) OpenEdition}

\section{Journals}

\section{Édition électronique}

URL : http://journals.openedition.org/studifrancesi/8912

DOI : 10.4000/studifrancesi.8912

ISSN : 2421-5856

\section{Éditeur}

Rosenberg \& Sellier

\section{Édition imprimée}

Date de publication : 1 octobre 2008

Pagination : 454-455

ISSN : 0039-2944

\section{Référence électronique}

Regina Bochenek-Franczakowa, «Robert L. Dawson, Confiscations at customs: banned books and the French booktrade during the last years of the Ancien Régime », Studi Francesi [En ligne], 155 (LII | II) | 2008, mis en ligne le 30 novembre 2015, consulté le 10 janvier 2021. URL : http://journals.openedition.org/ studifrancesi/8912; DOI : https://doi.org/10.4000/studifrancesi.8912

Ce document a été généré automatiquement le 10 janvier 2021.

\section{cc) (†)}

Studi Francesi è distribuita con Licenza Creative Commons Attribuzione - Non commerciale - Non opere derivate 4.0 Internazionale. 


\title{
Robert L. Dawson, Confiscations at customs: banned books and the French booktrade during the last years of the Ancien Régime
}

\author{
Regina Bochenek-Franczakowa
}

\section{RÉFÉRENCE}

ROBERT L. DAWSON, Confiscations at customs: banned books and the French booktrade during the last years of the Ancien Régime, Oxford, Voltaire Foundation, 2007 (SVEC 2006:07), pp. 315.

1 L'ouvrage s'inscrit dans la lignée des travaux de Robert Darnton consacrés à la production, édition et diffusion de la littérature clandestine en France au XVIII ${ }^{\mathrm{e}}$ siècle. L'A. explore les divers registres de la douane, cherchant les traces de la confiscation (au sens de suspension) des ouvrages imprimés arrivant à Paris de l'étranger ou de la province française. À part les deux registres examinés par Darnton, l'A. étudie divers autres dossiers, textes et sources d'archives.

2 Le volume se compose de deux volets: le premier contient des réflexions, informations et explications de l'A. lui-même sur tout ce qui forme ce phénomène complexe et plein de contradictions qu'est le livre prohibé au crépuscule de l'Ancien régime. Nous recevons d'inestimables précisions sur les lois, règles et règlements conçus dans le but de veiller à l'orthodoxie des contenus des livres et jamais appliqués de manière conséquente ni même rigide. L'A. nous trace les parcours possibles - et souvent sinueux - des livres condamnés, essaie de comprendre les motivations d'interdiction, mais en premier lieu, il attire notre attention sur les ambiguïtés et contradictions qui rendent ce tableau de plus en plus embrouillé. C'est que, comme l'A. tient à le démontrer, des années 1770 jusqu'à l'approche de la Révolution, le contrôle du commerce du livre importé à Paris devient de plus en plus problématique et confus dans l'application des 
règlements. L'autorité de l'État se trouve ainsi sapée par cette «relativité de proscription", signe du temps qui voit changer les mentalités, même chez des fonctionnaires d'État. Le second volet de l'ouvrage est constitué de onze appendices de longueur inégale. Ce sont des registres, listes et documents divers dont la plupart inédits. Il faut remarquer d'abord les listes et registres dont les plus larges sont: le catalogue de Poinçot de livres transférés de la Bastille qui fournit d'amples et précises informations sur les livres interdits («Appendix K»); le relevé des livres passant par la douane avec ou sans l'autorisation tacite («Appendix F»); enfin, la liste des «livres qui ont envoyé Pecquet à la Bastille» («Appendix D»). D'autre part, l'on trouve des fragments de textes, comme dans l'«Appendix C» où l'A. cite la discussion sur des livres interdits concrets dans la Correspondance secrète, politique et littéraire de Mettra, Imbert et alii.

3 Il est difficile d'apprécier ici toute la richesse de renseignements contenus dans ce volume, qui est d'une utilité inestimable pour tout chercheur se penchant sur le commerce du «livre dangereux» dans les dernières décennies de l'Ancien régime en France. Il témoigne aussi, d'une manière rigoureuse et précise, que la diffusion du livreobjet est toujours quelque chose de plus qu'un simple négoce et que les moyens mis à l'œuvre par l'autorité pour le contrôler mènent à des résultats imprévus. 